\title{
Asynchronous Preparation of Tonally Fused Intervals in Polyphonic Music
}

\author{
DAVID HURON \\ School of Music, Ohio State University
}

\begin{abstract}
An analysis of a sample of polyphonic keyboard works by J.S. Bach shows that synchronous note onsets are avoided for those harmonic intervals that most promote tonal fusion (such as unison, fifths and octaves). This pattern is consistent with perceptual research showing an interaction between onset synchrony and tonal fusion in the formation of auditory streams (e.g., Vos, 1995). The results provide further support for the notion that polyphonic music is organized so as to facilitate the perceptual independence of the concurrent parts.
\end{abstract}

Submitted 2007 October 25; accepted 2007 November 3.

KEYWORDS: auditory streams, voice leading, tonal fusion, onset synchrony

IN the perception of auditory scenes, a number of factors are known to influence the formation of auditory streams (Bregman, 1990; McAdams \& Bregman, 1979; van Noorden, 1975). Both time domain and frequency domain factors contribute to the perception of either separate or integrated sound images. In the case of concurrently sounding tones, two important factors are tonal fusion and onset synchrony. Tonal fusion is the tendency for two or more harmonically related tones to fuse and form a single auditory image. Onset synchrony is the tendency for two or more tones having coincident onsets to evoke a single auditory image.

Onset asynchronies as small as $10 \mathrm{~ms}$ have been shown to facilitate the segregation of two tones so they form independent sounds (Rasch, 1978). However, Vos (1995) has noted that the experimental paradigms used in such experiments employ cyclic (repeated) stimuli that make it easier to segregate the component sounds. Consequently, such experimental measures ought to be regarded as ideal threshold values rather than values typical for source separation in common listening situations. Using an experimental procedure that better approximates the uncertainties attending naturally-occurring sounds, Vos found that for non-cyclic stimuli, asynchronies of even $20 \mathrm{~ms}$ are insufficient to evoke segregation of the component tones. Larger amounts of asynchrony are necessary: Vos has suggested that for significant effects on perceptual separation to occur, asynchronies greater than 50 ms may be needed (Vos, 1995; p. 414). Beyond $50 \mathrm{~ms}$, larger asynchronies may well continue to facilitate the segregation of auditory sources. It is plausible that the ceiling effect for source segregation due to onset asynchrony may not appear until the inter-onset interval is $100 \mathrm{~ms}$ or longer. This latter value is more typical of the asynchronies implied in musical scores where notated asynchronies between two parts are rarely less than a sixteenth or thirty-second note in duration. At 96 beats per minute, for example, two notes whose onsets differ by a sixteenth-note duration would have a nominal asynchrony of $156 \mathrm{~ms}$.

In the case of polyphonic music, musical samples have already been shown to be consistent with the pursuit of asynchronous onsets between concurrent parts. Rasch (1981) carried out an analysis of vocal works by Praetorius, and showed that onset asynchrony between the notated parts increases as the number of voices is increased. Experiments by Huron (1989a) and Parncutt (1989) have shown that listeners' abilities to track auditory streams become degraded as the number of concurrent voices increases. Hence, the observed increase in asynchrony might be expected to compensate for the increased difficulty of parsing auditory scenes that contain many parts. Even in the case of two-part polyphonic music, Huron (1989b, 1993) showed that, compared with a meter-controlled distribution, Bach's 15 two-part Inventions exhibit a systematic tendency to avoid synchronous onsets between the parts.

In the case of tonal fusion, evidence also indicates that polyphonic music is organized so as to avoid tonally-fused intervals. Using data on tonal fusion collected by Stumpf (1890) and by DeWitt and Crowder (1987), Huron (1991a) showed that, compared with a pitch-proximity-controlled distribution of 
intervals, the frequency of occurrence of an interval (in polyphonic works) is negatively correlated with the degree to which that interval promotes tonal fusion. Moreover, a multiple regression analysis showed that 89 percent of the variance in Bach's interval "preference" (i.e., interval Z-scores) is accounted for by the twin goals of avoiding tonal fusion and pursuing tonal consonance. It is not simply the case that tonal fusion and tonal consonance influence the choice of harmonic intervals in Bach's polyphonic music. In light of the large R-squared value, these perceptual factors account for the majority of the compositional variance in Bach's choice of harmonic intervals. By way of summary, the existing research suggests that the negative effects of both tonal fusion and onset synchrony on the perceptual independence of auditory streams can be observed in the polyphonic scores of composers like Bach and Praetorius.

Possible interactions between tonal fusion and onset synchrony have been experimentally investigated by McAdams (1984), by Roberts and Bailey (1993a, 1993b) and most notably by Vos (1995). In Vos's Experiment II, listeners heard two successive two-tone dyads and were asked to judge whether any pitch was present in both dyads. Some dyads contained precisely synchronized onsets, whereas other dyads exhibited asynchronous onsets. Also, some dyads contained tones whose intervals were tuned to simple integer frequency ratios $(2: 3,3: 4,3: 5,5: 6$ and 11:12), whereas other dyads were mistuned (flat or sharp) by 15 cents. Figure 1 reproduces the most pertinent of Vos's results. The figure plots the mean percentage of correct identifications for the four conditions. Vos found a significant interaction between the synchronous/asynchronous conditions and the just/mistuned conditions. Note that the difference between the synchronous and asynchronous conditions is nearly twice as large for just intervals as it is for the mistuned intervals. Vos's results indicate that segregation is facilitated by asynchronous onsets more in the case of tonally-fused intervals than for less fused intervals. Or said another way, the most difficult stimuli to segregate are those that are both tonally fused and exhibit coincident onsets.

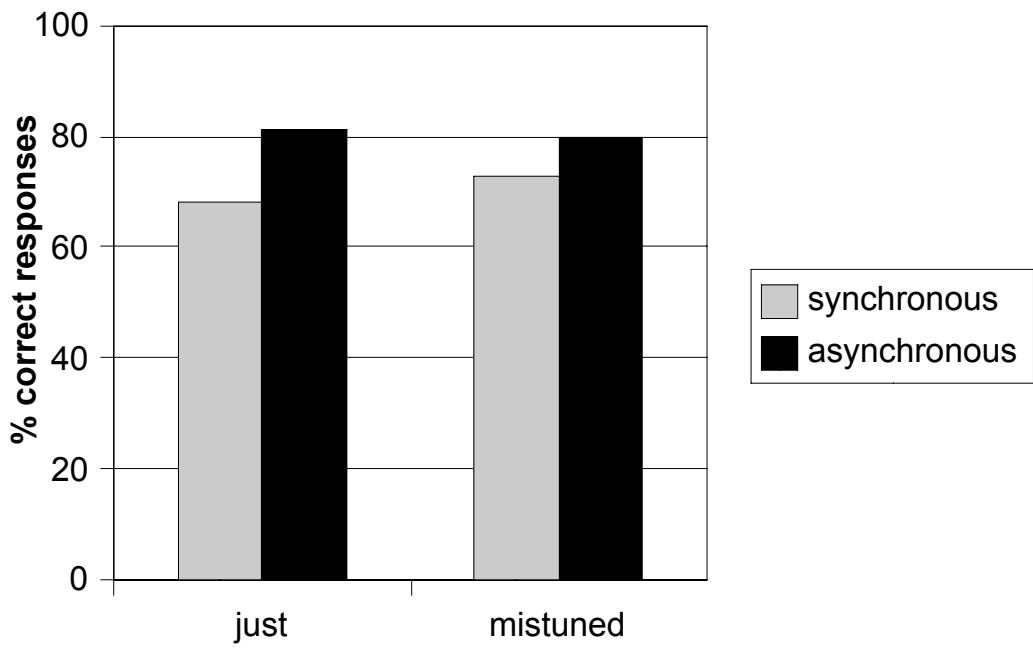

Fig. 1. Interaction of onset synchrony and interval tuning from Vos (1995) Experiment II. The figure shows the percent correct responses where listeners were asked to identify whether the highest pitches were the same in two successive two-note chords (dyads). In the synchronous condition, tone onsets were precisely coordinated. In the asynchronous condition, the lower tone in each dyad was delayed by $25 \mathrm{~ms}$. Intervals were either tuned according to just intonation (frequency ratios of 2:3, 3:4, 3:5, 5:6 and 11:12) or were mistuned (flat or sharp) by 15 cents. The chance response level is slightly less than 20 percent. Note that the difference between the synchronous and asynchronous conditions is nearly twice as large for just intervals as it is for mistuned intervals. This interaction indicates that perceptual segregation of the pitches is facilitated by asynchronous onsets more in the case of tonally-fused intervals than for less fused intervals.

Two caveats are noteworthy regarding Vos's experiment. In the first instance, Vos did not test stimuli involving the simpler frequency ratios of 1:1 (unison) and 1:2 (octave). These latter intervals are especially 
prone to tonal fusion; therefore the magnitude of the interaction between tonal fusion and onset synchrony may be understated in Figure 1. In addition, Vos amalgamated his analysis into in-tune/out-of-tune interval categories, and so no comparison was made between different interval sizes that might evoke more tonal fusion (e.g., 2:3) or less tonal fusion (e.g., 11:12). Once again, this would have the effect of understating the magnitude of the interaction between tonal fusion and onset synchrony.

The interaction between tonal fusion and onset synchrony in perceptual experiments is consistent with the theory that both of these factors contribute to a single perceptual phenomenon - namely, the formation of distinct auditory images. If a similar interaction between tonal fusion and onset synchrony was found in polyphonic musical organization, then such a finding would support the view that polyphonic composers avoid tonal fusion and onset synchrony for a single interlinked reason - namely, to maintain independent perceptual images of the musical parts or voices (Huron, 2001). In order to test this idea, a study of compositional practice was carried out.

\section{Hypotheses}

If interactions between tonal fusion and onset synchrony affect auditory streaming, and if a goal of polyphonic music is to maintain the perceptual independence of the musical parts, then we ought to be able to observe interactions between tonal fusion and onset synchrony in the polyphonic repertoire. Specifically, where the pitch interval between concurrent tones tends to promote tonal fusion, then an appropriate compositional strategy would be to avoid synchronous onsets for the notes forming the interval. For example, we would predict that intervals such as perfect fifths and octaves would be less likely to be formed by notes having coinciding onsets than for other intervals such as major thirds and minor sevenths.

We might therefore test the following hypothesis:

(H1) Harmonic intervals which most promote tonal fusion are more likely to be formed by notes having asynchronous onsets.[1]

\section{INTERLUDE}

It is appropriate to note that Hypothesis 1 might be construed as exactly contrary to well-established notions in music theory pertaining to the preparation of dissonances. Traditional analyses of the Western musical corpus have long shown that dissonant intervals tend to be "prepared" by having one note of the dissonance appear before the other (e.g., Zarlino, 1558; see also Wright, 1986; Wright \& Bregman, 1987[2]). Often, as in the suspension, a dissonant tone is sustained into the new sonority, and subsequently resolved to a less dissonant interval. This leads us to an alternative hypothesis:

(H2) Dissonant harmonic intervals are more likely to be formed by notes having asynchronous onsets.

Following Stumpf (1890), many music scholars have assumed that tonal fusion and tonal consonance are the same phenomenon, and that both arise from simple integer frequency ratios. If this were true, then Hypotheses 1 and 2 would indeed be contradictory and so mutually exclusive: we would necessarily be unable to find evidence consistent with both of these hypotheses. However, the extant research on tonal consonance does not support Stumpf's original view that consonance arises from tonal fusion. Indeed, Stumpf himself later abandoned his proposal that tonal fusion is the cause of tonal consonance. Studies by Greenwood (1961, 1990, 1991), Plomp and Levelt (1965), Kameoka and Kuriyagawa (1969a, 1969b) and Iyer, Hoglund, Aarden and Huron (1999) implicate critical band distances as the foremost factor in the perception of tonal consonance or sensory dissonance. This work shows that sensory consonance is only indirectly related to harmonicity or tonal fusion. The independence of these two phenomena can also be observed in the musical corpus itself. In Huron (1991a), Bach's choice of harmonic intervals was shown to be best explained by the simultaneous pursuit of tonal consonance and the avoidance of tonal fusion. In other words, both the extant perceptual research and the analytic studies do not rule-out the possibility that Hypotheses 1 and 2 may both be true. 


\section{METHOD}

In order to test Hypothesis 1, a study was initiated to measure the association between synchronous onsets and tonally-fused intervals in polyphonic musical practice. The same data provides a way of testing Hypothesis 2.

\section{Sample}

Hypothesis 1 is assumed to apply only in the case of music where the intention is to create multiple concurrent lines, parts, or voices whose perceptual independence is deemed important. Consequently, it is appropriate to limit our sample to the genre of music dubbed "polyphony." A suitable sample is available in polyphonic keyboard works by Johann Sebastian Bach. Two repertoires were selected for study: a two-part repertoire consisting of J.S. Bach's 15 two-part keyboard Inventions and a three-part repertoire consisting of the 26 three-part fugues in Bach's Well-Tempered Clavier. The two-part Inventions provided 5,608 harmonic intervals for analysis; the WTC sample provided 31,913 harmonic intervals.

\section{Procedure}

In the case of Bach's two-part Inventions the following measurements were made. For each successive sonority in each work, two items of information were determined: (1) the harmonic interval was measured (in semitones) between the two voices, and (2) it was determined whether the sonority was formed by the onset of just one note (asynchronously-formed interval) or by the onset of both notes (synchronouslyformed interval). In the case of the three-part works, the same procedure was used for each of the possible voice-pairings: treble/midvoice, bass/midvoice and treble/bass. In the three-part works, new intervals were calculated between voice-pairings only when one or both parts contained a note onset and neither part contained a rest. All measures were calculated from extant computer databases using the Humdrum Toolkit (Huron, 1995).

\section{RESULTS}

The results for Bach's two-part Inventions and three-part WTC fugues are given in Tables 1 and 2 respectively. For the three-part works, the interval tallies represent all three pairings of treble, bass and mid voices. The first column in each table identifies the interval size. For convenience, the intervals in these tables have been identified using common musical nomenclature - however, the actual intervals were measured in semitones. Hence, for example, an augmented sixth interval would be recorded as a minor seventh (i.e., 10 semitones in both cases). The ensuing columns identify the number of harmonic intervals that occurred in synchronous or asynchronous contexts. The fourth column indicates whether the tally of synchronous or asynchronous intervals predominates for the given interval size.

For convenience, the harmonic intervals for both sample repertoires have been grouped according to the traditional theoretical categories: perfect intervals (i.e., unisons, fifths, octaves, and compound equivalents), imperfect intervals (i.e., major and minor thirds, sixths, and compound equivalents), and dissonant intervals (i.e., major and minor seconds, sevenths, tritones, and compound equivalents). Intervals in the dissonant class tend to have complex frequency ratios and are known to exhibit relatively low tonal fusion. Intervals in the perfect-consonance class tend to have simpler frequency ratios and are known to exhibit relatively high tonal fusion. Intervals in the imperfect-consonance class have intermediate levels of tonal fusion.

Scanning down the fourth column for each table, the raw data leave no doubt about the association between interval class and whether the intervals are approached synchronously or asynchronously. For both the two-part and three-part repertoires, the majority of dissonant intervals occur in asynchronous contexts - as predicted by Hypothesis 2 . This result merely affirms theorists' traditional observations regarding the preparation of dissonances. By contrast, the imperfect consonances tend to occur predominantly in synchronous contexts. (Exceptions are marked with asterisks.) Finally, as predicted by Hypothesis 1, perfect consonances are skewed toward asynchronous occurrences. That is, perfect intervals such as fifths, octaves, twelfths, etc. tend to occur less frequently when the notes forming the interval have concurrent 
onsets. Given the large sample size and the large effect size, no statistical analysis is warranted here. The results are clearly consistent with both Hypotheses 1 and 2.

Table 1. J.S. Bach Two-Part Inventions

\section{Perfect Consonances:}

\begin{tabular}{|c|c|c|c|}
\hline $\begin{array}{c}\text { enharmonic } \\
\text { interval size }\end{array}$ & $\begin{array}{c}\text { \# of synchronous } \\
\text { intervals }\end{array}$ & $\begin{array}{c}\text { \# of asynchronous } \\
\text { intervals }\end{array}$ & $\begin{array}{c}\text { direction } \\
\text { of skew }\end{array}$ \\
\hline P1 & 5 & 7 & asynchronous \\
\hline P4 & 25 & 51 & asynchronous \\
\hline P5 & 51 & 66 & asynchronous \\
\hline P8 & 82 & 149 & asynchronous \\
\hline P11 & 92 & 209 & asynchronous \\
\hline P12 & 142 & 195 & asynchronous \\
\hline P15 & 111 & 158 & asynchronous \\
\hline P18 & 35 & 114 & asynchronous \\
\hline P19 & 34 & 85 & asynchronous \\
\hline P22 & 18 & 21 & asynchronous \\
\hline P25 & 2 & 3 & asynchronous \\
\hline P26 & 2 & 1 & synchronous*** \\
\hline Totals: & 599 & 1059 & \\
\hline
\end{tabular}

\section{Imperfect Consonances:}

\begin{tabular}{|c|c|c|c|}
\hline $\begin{array}{c}\text { enharmonic } \\
\text { interval size }\end{array}$ & $\begin{array}{c}\text { \# of synchronous } \\
\text { intervals }\end{array}$ & $\begin{array}{c}\text { \# of asynchronous } \\
\text { intervals }\end{array}$ & $\begin{array}{c}\text { direction } \\
\text { of skew }\end{array}$ \\
\hline m3 & 40 & 28 & synchronous \\
\hline M3 & 36 & 39 & asynchronous*** \\
\hline m6 & 139 & 50 & synchronous \\
\hline M6 & 253 & 55 & synchronous \\
\hline m10 & 342 & 129 & synchronous \\
\hline M10 & 256 & 122 & synchronous \\
\hline m13 & 164 & 125 & synchronous \\
\hline M13 & 247 & 101 & synchronous \\
\hline m17 & 217 & 73 & synchronous \\
\hline M17 & 109 & 64 & synchronous \\
\hline m20 & 40 & 21 & synchronous \\
\hline M20 & 27 & 16 & synchronous \\
\hline m24 & 23 & 6 & synchronous \\
\hline M24 & 8 & 4 & synchronous \\
\hline Totals: & 1901 & 832 & \\
\hline & & & \\
\hline
\end{tabular}




\section{Dissonances:}

\begin{tabular}{|c|c|c|c|}
\hline $\begin{array}{l}\text { enharmonic interval } \\
\text { size }\end{array}$ & $\begin{array}{c}\text { \# of synchronous } \\
\text { intervals }\end{array}$ & $\begin{array}{c}\text { \# of asynchronous } \\
\text { intervals }\end{array}$ & $\begin{array}{c}\text { direction } \\
\text { of skew }\end{array}$ \\
\hline $\mathrm{m} 2$ & 2 & 5 & asynchronous \\
\hline M2 & 7 & 18 & asynchronous \\
\hline TT & 26 & 33 & asynchronous \\
\hline $\mathrm{m} 7$ & 33 & 102 & asynchronous \\
\hline M7 & 5 & 51 & asynchronous \\
\hline $\mathrm{m} 9$ & 5 & 39 & asynchronous \\
\hline M9 & 45 & 123 & asynchronous \\
\hline $\mathrm{A} 11 / \mathrm{d} 12$ & 89 & 112 & asynchronous \\
\hline $\mathrm{m} 14$ & 69 & 118 & asynchronous \\
\hline M14 & 11 & 43 & asynchronous \\
\hline $\mathrm{m} 16$ & 9 & 36 & asynchronous \\
\hline M16 & 26 & 94 & asynchronous \\
\hline A18/d19 & 25 & 38 & asynchronous \\
\hline $\mathrm{m} 21$ & 14 & 22 & asynchronous \\
\hline M21 & 1 & 3 & asynchronous \\
\hline $\mathrm{d} 22$ & 0 & 1 & asynchronous \\
\hline $\mathrm{m} 23$ & 1 & 0 & synchronous*** \\
\hline M23 & 1 & 9 & asynchronous \\
\hline $\mathrm{m} 28$ & 0 & 1 & asynchronous \\
\hline Totals: & 369 & 848 & \\
\hline
\end{tabular}

Table 2. J.S. Bach WTC Three-part Fugues

Perfect Consonances:

\begin{tabular}{|c|c|c|c|}
\hline $\begin{array}{c}\text { enharmonic interval } \\
\text { size }\end{array}$ & $\begin{array}{c}\text { \# of synchronous } \\
\text { intervals }\end{array}$ & $\begin{array}{c}\text { \# of asynchronous } \\
\text { intervals }\end{array}$ & $\begin{array}{c}\text { direction } \\
\text { of skew }\end{array}$ \\
\hline P1 & 139 & 76 & synchronous*** \\
\hline P4 & 497 & 1131 & asynchronous \\
\hline P5 & 615 & 1176 & asynchronous \\
\hline P8 & 535 & 1234 & asynchronous \\
\hline P11 & 364 & 902 & asynchronous \\
\hline P12 & 591 & 817 & asynchronous \\
\hline P15 & 421 & 594 & asynchronous \\
\hline P18 & 103 & 268 & asynchronous \\
\hline P19 & 132 & 172 & asynchronous \\
\hline P22 & 36 & 39 & asynchronous \\
\hline P25 & 2 & 4 & asynchronous \\
\hline P26 & 1 & 3 & asynchronous \\
\hline Totals: & 3,436 & 6,416 & \\
\hline
\end{tabular}




\section{Imperfect Consonances:}

\begin{tabular}{|c|c|c|c|}
\hline $\begin{array}{c}\text { enharmonic interval } \\
\text { size }\end{array}$ & $\begin{array}{c}\text { \# of synchronous } \\
\text { intervals }\end{array}$ & $\begin{array}{c}\text { \# of asynchronous } \\
\text { intervals }\end{array}$ & $\begin{array}{c}\text { direction } \\
\text { of skew }\end{array}$ \\
\hline m3 & 910 & 700 & synchronous \\
\hline M3 & 729 & 643 & synchronous \\
\hline m6 & 816 & 809 & synchronous \\
\hline M6 & 1375 & 959 & synchronous \\
\hline m10 & 1485 & 714 & synchronous \\
\hline M10 & 1155 & 580 & synchronous \\
\hline m13 & 609 & 441 & synchronous \\
\hline M13 & 749 & 495 & synchronous \\
\hline m17 & 603 & 224 & synchronous \\
\hline M17 & 398 & 161 & synchronous \\
\hline m20 & 65 & 55 & synchronous \\
\hline M20 & 64 & 43 & synchronous \\
\hline Totals: & 8,958 & 5,824 & \\
\hline & & & \\
\hline
\end{tabular}

\section{Dissonances:}

\begin{tabular}{|c|c|c|c|}
\hline $\begin{array}{c}\text { enharmonic interval } \\
\text { size }\end{array}$ & $\begin{array}{c}\text { \# of synchronous } \\
\text { intervals }\end{array}$ & $\begin{array}{c}\text { \# of asynchronous } \\
\text { intervals }\end{array}$ & $\begin{array}{c}\text { direction } \\
\text { of skew }\end{array}$ \\
\hline m2 & 32 & 80 & asynchronous \\
\hline M2 & 206 & 357 & asynchronous \\
\hline TT & 538 & 625 & asynchronous \\
\hline m7 & 455 & 759 & asynchronous \\
\hline M7 & 125 & 212 & asynchronous \\
\hline m9 & 72 & 223 & asynchronous \\
\hline M9 & 284 & 575 & asynchronous \\
\hline A11/d12 & 522 & 454 & synchronous*** \\
\hline m14 & 297 & 457 & asynchronous \\
\hline M14 & 67 & 122 & asynchronous \\
\hline m16 & 48 & 100 & asynchronous \\
\hline M16 & 145 & 238 & asynchronous \\
\hline A18/d19 & 182 & 95 & synchronous*** \\
\hline Totals: & 2,973 & 4,297 & \\
\hline
\end{tabular}

\section{Rank-Order Correlation}

A more stringent test of Hypothesis 1 might entail a direct calculation of the correlation between the degree of tonal fusion for various intervals and the corresponding proportion of asynchronous onsets. This test is technically more tenuous since it will require many more assumptions. Nevertheless, calculating such a correlation may prove instructive. Given the similarity of the results for both the two-part and three-part repertoires, Table 3 amalgamates all of the data for all voice-pairings. The intervals shown are ordered roughly according to the degree of harmonicity-beginning with those intervals whose frequency ratios are most simple. Note that the dissonant intervals have been excluded. 
Table 3. Interval Tallies Ranked by Tonal Fusion

\begin{tabular}{|c|c|c|c|c|}
\hline interval & $\begin{array}{c}\text { frequency } \\
\text { ratio }\end{array}$ & $\begin{array}{c}\text { \# of synchronous } \\
\text { intervals }\end{array}$ & $\begin{array}{c}\text { \# of } \\
\text { asynchronous } \\
\text { intervals }\end{array}$ & $\begin{array}{c}\text { synchronous-to- } \\
\text { asynchronous } \\
\text { ratio }\end{array}$ \\
\hline P1 & $1: 1$ & 145 & 84 & 1.73 \\
\hline P8 & $1: 2$ & 617 & 1,383 & 0.45 \\
\hline P5 & $\sim 2: 3$ & 739 & 1,321 & 0.56 \\
\hline P12 & $\sim 1: 3$ & 733 & 1,012 & 0.72 \\
\hline P4 & $\sim 3: 4$ & 449 & 1,103 & 0.41 \\
\hline P15 & $1: 4$ & 532 & 752 & 0.71 \\
\hline M3 & $\sim 4: 5$ & 765 & 682 & 1.12 \\
\hline M6 & $\sim 3: 5$ & 1,628 & 1,014 & 1.61 \\
\hline M10 & $\sim 2: 5$ & 1,411 & 702 & 2.01 \\
\hline m3 & $\sim 5: 6$ & 950 & 723 & 1.31 \\
\hline m6 & $\sim 5: 8$ & 955 & 859 & 1.11 \\
\hline
\end{tabular}

Four important caveats must be noted at this point. In the first instance, there is little experimental evidence concerning the amount of tonal fusion elicited by various interval sizes. There is no general agreement in the literature concerning the rank ordering of fused intervals beyond the sequence: P1, P8, P5. For example, the placement of P4 is contentious: experimental data collected by DeWitt and Crowder (pp. 77, 78) paradoxically suggests that major sevenths (using pure tones) are more prone to tonal fusion than are perfect fourths - perhaps because listeners interpret the tones as mistuned $1^{\text {st }}$ and $2^{\text {nd }}$ harmonics. In the second instance, equally tempered intervals correspond only roughly with just intervals. In the case of the unison (P1), octave (P8) and double-octave (P15) intervals, the equally-tempered and just intervals are the same. For the perfect fifth (P5) and twelfth (P12), the discrepancy is 2 cents. However, for the major third (M3) and sixth (M6), the discrepancies are 14 cents and 16 cents respectively. DeWitt and Crowder (1987) showed that tonal fusion is (slightly) more pronounced in just intonation than in equal temperament tunings. However, the degree of tonal fusion for different interval types was found to correlate closely across the two tuning systems (p.77). For intervals of an octave or less in size, DeWitt and Crowder found the rank ordering of intervals in promoting tonal fusion remains the same in both tuning systems. Nevertheless, any comparisons must be regarded as only approximate. In the third instance, caution is necessary in interpreting the influence of timbre: the repertoire measures pertain to complex tones of variable and unknown spectral content whereas most of the experimental observations involve sine tones. Finally, a fourth concern relates to the exclusion of dissonant intervals. Any correlation is sensitive to the end points, and Table 3 does not include dissonant intervals which would necessarily reduce any presumed correlation between onset asynchrony and tonal fusion. The general assumption is that tonal fusion shows a floor effect and that the dissonant intervals show no less propensity for tonal fusion than the imperfect consonances.

Keeping the above caveats in mind, we may nevertheless ask to what degree does the amount of tonal fusion predict the tendency to use asynchronous rather than synchronous onsets? The right-most column of Table 3 indicates the ratio of synchronous-to-asynchronous note onsets for the combined data. Hypothesis 1 would predict that these ratios ought to increase with decreasing tonal fusion. That is, the ratio values should increase as we proceed down the table. Spearman's rank-order correlation for the synchrony/asynchrony ratio is $+0.40(\mathrm{df}=9$; N.S.). Although this correlation is skewed in a direction consistent with Hypothesis 1, it is not statistically significant. Inspection of the ratio values given in Table 3 reveals that a single value accounts for a large reduction in the correlation-namely the value for the perfect unison. Compared with the other values in the table, this ratio is unusually large and is not consistent with Hypothesis 1 . This raises the possibility that unison intervals are confounded by some other factor. 
At least three mitigating factors might account for this anomaly. In the first instance, asynchronous onsets for a unison-especially in keyboard works - are not likely to increase stream segregation. In fact, successive repetition of a single pitch is more likely to encourage the perception of a single stream. Experiments involving interleaved melodies (Dowling, 1973) produce notable stream capture when successive unisons occur. In addition, successive repetitions of a single pitch tend to increase that note's salience or noticeability. Given a polyphonic context where all voices are presumed to deserve equal weight, such increased salience may draw unwelcome attention to a single pitch. Finally, a further mitigating factor may arise from voice "crowding" or "collisions." Huron (1991b) demonstrated a significant reluctance to allow part-crossing in polyphonic musical practice. However, restrictions of pitchrange frequently cause parts to come into close proximity. Since harmonic considerations limit the possible pitch choices, unisons may be the "interval of last resort" when two voices are close in pitch. If these three factors are accepted as mitigating factors, then omitting unisons from the correlational measure seems warranted, with the consequence that the rank-correlation rises to a statistically significant $+0.75(\mathrm{df}=8$; $p<0.01)$. Given the number of assumptions involved in this calculation, however, little confidence should be placed in this result.

\section{CONCLUSION}

In Huron (1993) it was shown that synchronous note onsets tend to be minimized in Bach's polyphonic compositions. In Huron (1991a) it was shown that Bach tends to minimize the occurrence of intervals that promote tonal fusion. If both of these phenomena are related to the maintenance of segregated auditory images, then an interaction between these two phenomena would be predicted: when tonally-fused intervals appear in Bach's polyphonic music, further efforts would be made to avoid onset synchronization. As we have seen, such an interaction is evident in samples of two-part and three-part polyphonic compositions by Bach. Those intervals most likely to evoke tonal fusion-namely the perfect intervals-tend to be asynchronously prepared in a manner akin to the asynchronous preparation of dissonances.

The results of the present study are consistent with the interpretation that the avoidance of tonal fusion and the avoidance of onset synchrony are linked to a single goal. Although other interpretations are possible, the most straightforward interpretation of the shared goal is the perceptual independence of the musical parts. More generally, the results contribute to the view that compositional practice in polyphonic music shows significant adaptations consistent with the extant research pertaining to auditory stream segregation. At least in the case of J.S. Bach, there is abundant evidence that the composer has organized the voice-leading so as to assist listeners in following each of the concurrent voices.[3]

\section{NOTES}

[1] The term "harmonic interval" is used in the normal musical sense of the distance between any two concurrent pitches. The term is not intended to imply that the intervals coincide with the harmonic series.

[2] James Wright has proposed an interesting interpretation of dissonant preparation. Wright has suggested that dissonance is related to auditory streaming. Concurrent tones that participate in highly segregated auditory streams are thought to evoke less dissonance than if the tones are perceived as belonging to the same stream. If this interpretation is correct, then any composer wishing to reduce the perceived dissonance of a passage would be advised to prepare the dissonant intervals using asynchronous onsets.

[3] This research was carried out while the author was a visiting scholar at the Center for Computer Assisted Research in the Humanities, Stanford University. Thanks to Scott Van Duyne for comments on an earlier draft of this paper. 


\section{REFERENCES}

Bregman, A. S. (1990). Auditory Scene Analysis: The Perceptual Organization of Sound. Cambridge, MA: MIT Press.

DeWitt, L. A., \& Crowder, R. G. (1987). Tonal fusion of consonant musical intervals: The oomph in Stumpf. Perception \& Psychophysics, Vol. 41, No. 1, pp. 73-84.

Dowling, W. J. (1973). The perception of interleaved melodies. Cognitive Psychology, Vol. 5, pp. 322-337.

Greenwood, D. D. (1961). Critical bandwidth and the frequency coordinates of the basilar membrane. Journal of the Acoustical Society of America, Vol. 33, No. 4, pp. 1344-1356.

Greenwood, D. D. (1990). A cochlear frequency-position function for several species -- 29 years later. Journal of the Acoustical Society of America, Vol. 87, No. 6, pp. 2592-2605.

Greenwood, D. D. (1991). Critical bandwidth and consonance in relation to cochlear frequency-position coordinates. Hearing Research, Vol. 54, No. 2, 164-208.

Huron, D. (1989a). Voice denumerability in polyphonic music of homogeneous timbres. Music Perception, Vol. 6, No. 4, pp. 361-382.

Huron, D. (1998b). Voice Segregation in Selected Polyphonic Keyboard works by Johann Sebastian Bach. Unpublished doctoral dissertation, University of Nottingham.

Huron, D. (1989c). Characterizing musical textures. Proceedings of the 1989 International Computer Music Conference, San Francisco: Computer Music Association, 131-134.

Huron, D. (1991a). Tonal consonance versus tonal fusion in polyphonic sonorities. Music Perception, Vol. 9, No. 2, pp. 135-154.

Huron, D. (1991b). The avoidance of part-crossing in polyphonic music: Perceptual evidence and musical practice. Music Perception, Vol. 9, No. 1, pp. 93-104.

Huron, D. (1993). Note-onset asynchrony in J.S Bach's two-part inventions. Music Perception, Vol. 10, No. 4, pp. 435-444.

Huron, D. (1995). The Humdrum Toolkit Reference Manual. Menlo Park, California: Center for Computer Assisted Research in the Humanities.

Huron, D. (2001). Tone and Voice: A derivation of the rules of voice-leading from perceptual principles. Music Perception, Vol. 19, No. 1, pp. 1-64.

Huron, D. (2007). The role of embellishment tones in the perceptual segregation of concurrent parts. Empirical Musicology Review, Vol. 2, No. 4, pp. 123-139.

Iyer, N., Aarden, B., Hoglund, E. \& Huron, D. (1999). Effect of intensity on sensory dissonance. Journal of the Acoustical Society of America, Vol. 106, No. 4, pp. 2208-2209.

Kameoka, A., \& Kuriyagawa, M. (1969a). Consonance theory Part I: Consonance of dyads. Journal of the Acoustical Society of America, Vol. 45, pp. 1451-1459.

Kameoka, A., \& Kuriyagawa, M. (1969b). Consonance theory Part II: Consonance of complex tones and its calculation method. Journal of the Acoustical Society of America, Vol. 45, pp. 1460-1469. 
McAdams, S. (1984). Spectral Fusion, Spectral Parsing and the Formation of Auditory Images. Unpublished doctoral dissertation, Stanford University, Stanford, CA.

McAdams, S., \& Bregman, A. S. (1979). Hearing musical streams. Computer Music Journal, Vol. 3, No. 4, pp. 26-43.60,63.

Parncutt, R. (1989). Pitch properties of chords of octave-spaced tones. Speech Transmission Laboratory Quarterly Progress and Status Report (Royal Institute of Technology - Stockholm), Vol. 1, pp. 25-36.

Plomp, R., \& Levelt, W. J. M. (1965). Tonal consonance and critical bandwidth. Journal of the Acoustical Society of America, Vol. 37, pp. 548-560.

Rasch, R. A. (1978). The perception of simultaneous notes such as in polyphonic music. Acustica, Vol. 40, pp. 21-33.

Rasch, R. A. (1981). Aspects of the Perception and Performance of Polyphonic Music. Doctoral dissertation, Elinkwijk BV, Utrecht, The Netherlands.

Roberts, B., \& Bailey, P. J. (1993a). Spectral pattern and the perceptual fusion of harmonics. I. The role of temporal factors. Journal of the Acoustical Society of America, Vol. 94, No. 6, pp. 3153-3164.

Roberts, B., \& Bailey, P. J. (1993b). Spectral pattern and the perceptual fusion of harmonics. II. A special status for added components? Journal of the Acoustical Society of America, Vol. 94, No. 6, pp. 3165-3177.

Stumpf, C. [K.] (1890). Tonpsychologie (2 vols.) Leipzig: Verlag S. Hirzel.

Van Noorden, L. P. A. S. (1975). Temporal Coherence in the Perception of Tone Sequences. Doctoral dissertation, Technical University Eindhoven, Eindhoven, The Netherlands.

Vos, J. (1995). Perceptual separation of simultaneous complex tones: the effect of slightly asynchronous onsets. Acta Acustica, Vol. 3, No. 5, pp. 405-416.

Wright, J. K. (1986). Auditory Object Perception: Counterpoint in a New Context. Unpublished masters thesis, McGill University, Montréal, PQ.

Wright, J. K. \& Bregman, A. S. (1987). Auditory stream segregation and the control of dissonance in polyphonic music. Contemporary Music Review, Vol. 2, pp. 63-93.

Zarlino, G. (1558). Le istitutioni harmoniche III. Venice: Francesco Senese; reprint edition, New York: Broude Brothers, 1965. Trans. by Guy Marco and Claude Palisca as The Art of Counterpoint. New York: W.W. Norton, 1968. 